\title{
As Seqüelas Psicológicas da Tortura
}

\author{
Torture Psychologics sequels
}

Alfredo

Guillermo Martín

Universidade Federal do Rio Grande 


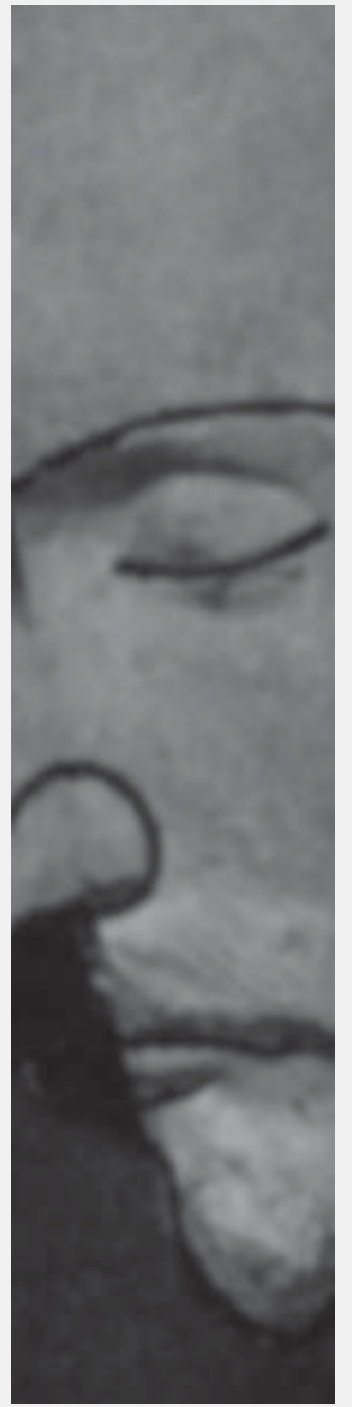

Resumo: Analisam-se, no texto, as seqüelas psicológicas da tortura, sendo esta compreendida como instituição do Estado e como experiência-limite em diferentes aspectos (as três etapas do processo traumatizante, principais seqüelas somáticas, retraumatização). Estuda-se o incremento das psicoses, a alta porcentagem de suicídios, as dificuldades de reinserção social, as seqüelas crônicas trans-geracionais e a taxa de mortalidade muito superior à normal. Desenvolve-se uma análise detalhada das questões ligadas à indenização das vítimas. Propõem-se instrumentos diagnósticos e terapêuticos apropriados, baseando-se numa crítica clínica do PTSD, numa ampla experiência pessoal e numa bibliografia internacional atualizada.

Palavras-chave: tortura, seqüelas psicológicas, processo traumáticos, psicodiagnóstico.

Abstract: This text analyses torture psychological sequels, considering torture as a state institution and as a limit experience in different aspects (the three steps of the traumatizing process, the main somatic sequels and re-traumatizing). It is also studied the psychosis increment, the high percentage of suicide, the difficulty of social reinsertion the cronic transgenerational sequels and the mortality rate, much higher than the normal rate.The text develops a detailed analysis about the indemnity os victims and diagnostics and therapy methods are proposed, based on a critic of PTSD, on a large personal experience and on na up-to-date bibliography.

Key words: torture, psychologics sequels, traumatizing process, psychodiagnostics.

Este pequeno trabalho foi escrito como parecer técnico elaborado para a Comissão de Direitos Humanos do Conselho Regional de Psicologia, Região IV - Minas Gerais, em julho de 2001, sendo encomendado e aprovado pela Comissão Estadual de Direitos Humanos de Minas Gerais com o objetivo de dar cumprimento às leis sobre indenização dos exprisioneiros da ditadura militar submetidos a torturas. Logo em 2004, pela passagem dos 40 anos da ditadura militar, foi apresentado, em forma oral, no Seminário "Repressão e Medo", organizado pela Comissão de Acervo da Luta contra a Ditadura e a Comissão de Indenização a ex-Presos Políticos, da Assembléia Legislativa do Estado de Rio Grande do Sul.

Ele aspira a recolher e apresentar algumas das experiências, tanto pessoais como de outros colegas latino-americanos e europeus, que sintetizam o esforço conjunto de muitos anos, trabalhando de maneira solidária com as pessoas que têm sofrido torturas e outras violações graves dos direitos humanos.

\section{Pensar e dizer a tortura e $\mathrm{O}$ genocídio implica um novo estatuto da palowra na sua relação coma crueldade e inaugura uma nova dimensão da função política da palowra.}

Michel de Certeau 
Com efeito, trabalhei primeiro no Brasil, acolhendo, como psicoterapeuta, os refugiados latino-americanos a partir de 1980; a seguir, na França, como psicólogo coordenador da Consultation Psychologique des Migrants, Réfugiés et Démandeurs d'Asile, assim como de três redes regionais de atendimento etnopsicológico, organizadas pelo Comitê Médico Social para Saúde dos Migrantes de Toulouse', nas quais são acolhidas anualmente centenas de refugiados e vítimas da tortura do mundo todo.

Não temos nenhuma pretensão à verdade, mas, sim, a de provocar o diálogo, aprofundar a reflexão e a renovação das práticas $1 O N G$ pioneira que funciona, a partir de 1974, no sul da França, com equipes transdisciplinares nas áreas da saúde mental e física, educação, integração social e cultural.

2 Ver René Lourau, (1979) El Estado inconsciente.Barcelona:Kairós; Baremblitt, G. (1984) 0 inconsciente institucional, Petrópolis:Vozes; Félix Guattari (1992) Chaosmose. Paris:Galilée.

3 Segundo dados oficiais da Ouvidoria da Polícia de Belo Horizonte, Minas Gerais.

4 Por exemplo, as opiniōes da Dra. Paz Rojas Baeza, do CODEPU (Corporación de Promoción y Defensa de los Derechos del Pueblo), do Chile, ¿Qué se Entiende por Tortura? Su Diagnóstico, in La Tortura y otras Violaciones de los Derechos Humanos. Simposio de Guatemala, 2000, e do Dr. Marcelo Viñar, Exil et Torture, ed. Denöel, Paris, 1989.

5 Marcelo Viñar, Exil et Torture, op.cit.

6 Sylvia Bermann, Sociedad, Psicología y Tortura en América Latina, in Efectos Psicosociales de la Represión Politica, sus Secuelas en Alemania, Argentina y Uruguay. Córdoba: Argentina, Instituto Goethe, 1994.

suspenso, por agora, todo o referente à descrição dos diferentes tipos de tortura, das diretrizes políticas que a ordenam, dos dispositivos institucionais e financeiros que a possibilitam, do envolvimento dos torturadores com os aparelhos do Estado assim como dos debates jurídicos, das campanhas internacionais contra a tortura, etc., já tratados na bibliografia.

Vamos considerar a tortura não como um efeito acidental, um "excesso" produzido por um sádico isolado, mas como uma instituição política do Estado ${ }^{2}$, planejada, ainda em funcionamento, produtora de subjetividade ${ }^{1}$ tanto nas suas primeiras vítimas diretas como nas suas famílias e descendentes e no conjunto do tecido sóciohistórico, incluindo os profissionais da saúde mental.

Queremos salientar não só a gravidade das seqüelas no passado, mas a vigência atual e a prospectiva da questão, lembrando a condenação do Brasil, pela ONU, por fatos de tortura, em meados de 2001, assim como a terrível estatística: mais de uma dúzia de denúncias de tortura por dia só em Belo Horizonte (MG) e mais de 2400 novas denúncias nos anos 2000-2001 ${ }^{3}$.

\section{A sintomatologia e as seqüelas}

Se bem exista um consenso entre os profissionais no sentido de dizer que não há uma patologia específica da tortura, uma sintomatologia unívoca que permita fazer um diagnóstico claro e propor um tratamento efetivo ${ }^{4}$, tentaremos sintetizar as principais coincidências nas diferentes orientações clínicas dos colegas que se têm debruçado sobre a situação das vítimas da tortura.

O processo traumatizante (ou "a demolição", no dizer de Marcelo Viñar ${ }^{5}$ ) comporta três etapas:
- a primeira e mais conhecida tem como alvo a destruição da pessoa, dos seus valores e convicções;

- a segunda é uma experiência limite de desorganização da relação do sujeito consigo mesmo e com o mundo, é a demolição propriamente dita, também conhecida como "esvaziamento narcisista", onde é usurpada a identidade e a história do sujeito;

- na terceira, abre-se a possibilidade de "resolução" da crise dessa situação-limite perante a organização de uma conduta substitutiva em maior ou menor consonância com os "valores" do torturador e daqueles que o comandam ${ }^{6}$.

Um dos aspectos centrais da tortura é que ela constitui uma "uma experiência extrema que 
produz sempre marcas e transforma o destino (...) o torturado se apresenta como a testemunha encarnada de uma ferida que concerne à humanidade inteira. Seu corpo ferido se oferece como símbolo, como bandeira onde se inscreve o que nele foi atingido e que Robert Antelme chama de "o sentimento de pertença à espécie humana", no dizer de Viñar ${ }^{7}$.

Assim, "o clima de terror generalizado e a institucionalização da tortura (...) se traduzem, na subjetividade, como perda do apoio social necessário ao funcionamento psíquico e com a interiorização do terror (...) com o abalamento da matriz da constelação identificatória..." ${ }^{8}$.

Esse processo, de uma violência inusitada em todos os níveis, deixa sempre as suas seqüelas. As seqüelas somáticas mais freqüentes são: danos cefálicos, perda do conhecimento, infecções com compromisso cefálico, cefaléias, neuralgias e mialgias, debilidade orgânica geral, com emagrecimento e anorexia, cardialgias, dores estomacais e diarréias, dores generalizados no corpo, cicatrizes, contusões, hematomas, escoriações, problemas sexuais (impotência, esterilidade, afecções ginecológicas, etc.), doenças respiratórias, fraturas e queimaduras várias, sofrendo o torturado, em geral, seqüelas crônicas por mais de três anos ${ }^{9}$.

Assim, por exemplo, no caso de Marcos Arruda, aparece "uma seqüela; é a do antebraço esquerdo, que tem um edema crônico do pulso até o cotovelo. ArrebentaramIhe os vasos linfáticos no pau-de-arara e nas algemas móveis (que apertam com qualquer movimento), tendo recomendado os médicos que evite qualquer infecção ali, pois não há mais defesa do sistema imunológico. $O$ imunologista que consulta com relativa regularidade deu-lhe um atestado de que essa lesão foi causada pela tortura. Em diversas ocasiões, nessas últimas duas décadas, ele tem tido infecções que começam num dedo e se espalham pelo antebraço na forma de pintas vermelhas e inchação... no ombro direito, ainda carrega as marcas de queimaduras de cigarro... no dedo mínimo do pé, tem uma cicatriz de queimadura com choques elétricos... um traumatismo no pau-de-arara deixou uma diferença notória à altura do ombro esquerdo..." ${ }^{10}$

É de assinalar que nem sempre é possível encontrar lesões físicas claramente vinculadas à tortura, devido, principalmente, aos métodos utilizados, cada vez mais sofisticados precisamente para "não deixar provas". Contudo, deve-se ter em consideração que algumas lesões traumáticas podem produzir seqüelas tardias, mesmo nas pessoas que não tinham nenhum problema de saúde prévio às torturas; cuidadosos exames médicos podem ser necessários para despistar lesões escondidas por trás de outros sintomas.

Quanto às seqüelas psicológicas, dificilmente enquadráveis na semiologia clássica, são provocadas tanto pela situação mesma da tortura (métodos diversos, seqüências e períodos variáveis, associadas a outras circunstâncias traumáticas - tortura de outro membro da família, violação, simulacros de fuzilamento, desaparecimento, exílio, etc.), pelos traumatismos físicos e as suas seqüelas fisiológicas como pelo refinamento das próprias torturas psicológicas utilizadas ("Os vamos enloquecer..." dizia um torturador argentino) e a significação social e política que fora dada a esses gravíssimos fatos (a impunidade judicial dos torturadores, a cumplicidade governamental e institucional, o silêncio da mídia, o esquecimento, a rejeição, etc.).

As seqüelas mais freqüentes são: os problemas identitários, os processos dissociativos graves, os comportamentos regressivos, os lutos não
7 op.cit. p.164.

8 M. Viñar, ibid.

9 Dres. Ricardo Loewe Reis, Javier Sam e Alejandro Cerde García, equipe de Salud Mental de ACAT (Acción de Cristianos por la Abolición de la Tortura-Sección México), Reporte de Investigación de los Sobrevivientes de la Tortura de la Región de los Loxichas, Oaxaca, in La Torturay otras Violaciones, op.cit.

10 Ver o depoimento da mãe, Lina Penna

Sattamini, Esquecer? Nunca Mais...Rio de Janeiro:Produtor Editorial Independente, 2000. 
$11 \mathrm{Dr}$. Leo Eitinger, Prisión en Campo de Concentración $y$ Traumatización Psiquica, in Represión $y$ Olvido: Efectos Psicológicos y Sociales de la Violencia Politica dos Décadas Después. Montevideo: Roca Viva, 1995, e Dr.Hans Stoffels, Paisajes Terroríficos del Alma, Posibilidades y Limites de la Psicoterapia con Perseguidos, in Efectos Psicosociales de la Represión Política, sus Secuelas en Alemania, Argentina y Uruguay, op.cit.

12 Dados dos estudos de Eitinger (op.cit.) e de María del Rosario Arregui de Azpiroz, Papel de las Instituciones de Derechos Humanos en la Atención a las Víctimas de la Violencia Organizada, in Represión y Olvido... (op.cit.).

13 Des.Fiorella.Perrone y $D$. González, equipe RAJP (Red de Apoyo por la Justicia y la Paz), Experiencia Venezolana de Abordaje Integral en Atención a las Víctimas de la Tortura, in La Tortura $y$ otras Violaciones, op.cit. pp. 61/75.

14 Jean Améry psiquiatra francês e exdetido, citado por Stoffels, op.cit.

15 Viktor Frankl. Un Psicólogo en un Campo de Concentración, in El Hombre en Busca de Sentido. Barcelona: Herde, 1994.

16 ürgen Müller-Hohagen, Casi Cincuenta Años Después. Experiencias y Reflexiones sobre el Trabajo Psicoterapéutico en Alemania con los Perseguidos y sus Descendientes, in Efectos Psicosociales de la Represión., op.cit.

17 Ver René Lourau. A Análise Institucional. Rio de Janeiro:Vozes, 1975. elaborados, a angústia crônica, a ansiedade e a depressão, a insônia persistente, os pesadelos, a repetição, os transtornos neuróticos ou psicóticos, as alterações dos hábitos alimentares, sexuais, etc., associadas à alta irritabilidade, com crises de clausura mais ou menos graves, os sentimentos de culpabilidade e de vergonha, de perseguição e de dano permanente, a incapacidade de trabalho e perda profissional, o isolamento, os transtornos da memória, da percepção e da atenção (estado de alerta permanente), as dificuldades relacionais com o casal, a família, etc. São assinaladas as freqüentes e crescentes dificuldades de inserção laboral.

Vale assinalar a persistência dos sentimentos de tremor, de se sentir indefensível, e os transtornos do esquema corporal; lembramos como um dos mais graves a levar em conta o incremento no índice de psicoses (cinco vezes maior que o normal) ${ }^{11}$ e a alta porcentagem de suicídios consumados (entre 16\% e 23\% maior que na população normal) ${ }^{12}$.

Segundo a experiência internacional e a minha própria, essa complexa fenomenologia desborda qualquer quadro nosográfico préestabelecido (ver os trabalhos do Uruguai, Argentina, Chile e da Venezuela ${ }^{13}$, assim como os trabalhos europeus já citados).

A maioria desses traumatismos pode deixar seqüelas crônicas ou de aparecimento tardio, periódico ou por surpresa, muitos anos depois. Como diz Jean Améry, aqueles que foram torturados continuam sendo torturados ${ }^{14}$. É necessário ressaltar que muitas das vítimas não têm sido beneficiadas por nenhuma consulta psicoterapéutica ou médica após a sua liberação, o que pode produzir, como grave efeito secundário, o "enquistamento" ou "congelamento" da situação traumática como seqüela suplementar. Isso pode trazer dificuldades especiais no processo terapêutico.
Viktor Frankl, na sua dupla condição (ex-detido em Auschwitz e profissional da saúde mental ${ }^{15}$ ), assinala uma das principais dificuldades, também ressaltada por outros autores conhecidos (Primo Levi, Bettelheim, etc.), a incomunicabilidade do traumatismo psíquico: "Não nos agrada falar das nossas vivências; àqueles que estiveram nos campos, não precisamos nada dizer; para aqueles que não estiveram, não poderemos fazer compreensível o que se passava no nosso interior e o que ainda se passa em nós".

Uma outra consideração de importância se refere às seqüelas produzidas pela retraumatização, ou reativação das situações traumáticas vividas na tortura devido à impunidade dos torturadores, às leis de anistia, à continuidade da repressão, à negação do reconhecimento social e jurídico dos danos sofridos, assim como aos erros profissionais que nós, os profissionais da saúde, podemos cometer. Muitas pessoas torturadas, assim como os seus descendentes, apresentam, com certa freqüência, o temor de uma dependência, de cair numa "entrega" ao terapeuta, se exporem e logo ficarem abandonados no vazio $^{16}$.

Já Viñar (op.cit.) alertava contra "o maniqueísmo de indenes e afetados que se joga na paródia terapêutica dos consultórios", sugerindo que "só conjugando a capacidade de sofrer é que se abre a possibilidade de uma eficácia terapêutica". Isso tem a ver com a análise das implicações dos profissionais ideológicas, libidinais, materiais-, desenvolvida por Lourau ${ }^{17}$ : não há lugar para qualquer tipo de "neutralidade do psicoterapeuta". Por outro lado , a medicalização da nomenclatura nos dá a ilusão de "saber alguma coisa" sobre a "patologia", mas, sobretudo, nos tranqüiliza: o "doente" é o "outro", e não eu. Viñar diz ainda: "Alojar o mal na "seqüela", nos confins 
de uma alma atormentada, nos labirintos intrapsíquicos da vítima, deixa de lado o fato que, na epidemia, o que importa não é só isolar e tratar os doentes, mas ver como o mal se difunde e contagia" ${ }^{18}$.

\section{Morbidade}

Existem sérias dificuldades para compreender e quantificar esse "contagio": o número de enfermidades ocorridas num certo período de tempo e num espaço determinado, no universo-alvo das vítimas de tortura, levandose em conta que muitas delas tiveram que sair em exílio e não retornaram, outras não se apresentaram para fazer as denúncias correspondentes e nem sequer para receber os cuidados terapêuticos necessários.

Podemos afirmar que não há vítimas da tortura que não tenham sofrimentos devido às seqüelas psicológicas e físicas e também que todas elas deveriam ter acesso fácil, anônimo e gratuito aos cuidados terapêuticos de que necessitam e aos quais têm direito. Isso pressupõe um desafio tanto para os profissionais como para as instituições (conselhos, hospitais, fundações, etc.) que têm por missão o cuidado da saúde pública.

É de ressaltar que as seqüelas psicológicas da tortura são crônicas e têm duração transgeneracional; assim, por exemplo, foi demonstrado com descendentes de famílias de judeus exterminadas nos campos de concentração nazistas. Com efeito, os grupos terapêuticos realizados em Paris ${ }^{19}$, reunindo familiares da terceira geração da "Shoah", têm evidenciado diversos sintomas desses traumatismos, presentes na afiliação, na memória familiar, nos "buracos negros" da história de cada um, nos silêncios do impossível de dizer e simbolizar.
O mesmo se tem verificado em outras situações históricas, por ex., no Uruguai, onde a consulta dos primeiros protagonistas da violência repressiva nos anos 70 foi paulatinamente substituída pela segunda e terceira geração ${ }^{20}$. Ressaltamos que, na experiência dos colegas, só cerca de $20 \%$ da população-alvo demanda e aceita a consulta psicoterapêutica.

Uma estimativa próxima da cronicidade traumática (ainda que em outra população alvo) assinala que, nos Estados Unidos, estimase entre 560.000 e 800.000 as vítimas da neurose traumática de guerra, ou seja, um de cada quatro soldados que combateu no Vietnam. Isso levou à criação de mais de 200 centros de atenção psicológica para os veteranos e suas famílias depois de 1979, com um orçamento de US\$ 47 milhões $^{21}$.

Também na França, muitos psiquiatras e psicólogos confirmam que aproximadamente 350.000 antigos soldados atuantes na guerra da Argélia (1954-1962) sofreriam de perturbações psicológicas mais ou menos invalidantes, de aparição imediata ou tardia, devido a sua participação direta ou indireta nas torturas. Um de cada quatro é a estimativa feita, mas não existem ainda dados epidemiológicos, reclamados há muito tempo pelos especialistas $^{22}$.

Sabe-se, também, que a quantidade de hospitalizações, doenças, intervenções cirúrgicas, etc., são muito mais freqüentes entre os sobreviventes da tortura que entre a população normal. Assim, num estudo muito completo feito na Noruega pelo Dr. Leo Eitinger, ${ }^{23}$ por encargo do governo, com os sobreviventes das torturas nos campos de concentração nazistas, escolheu-se uma amostra representativa de 500 ex-prisioneiros que foi cotejada com outros 500 cidadãos
18 Marcelo Viñar, Reflexiones, in Efectos Psicosociales de la Represión Politica, op.cit.

19 Equipe de Psicoterapeutas Interculturales do Centre Georges Devereux, Service Dr. Tobie Nathan, Universidade Paris VIII, 1989.

20 Victor Giorgi, Represión y Olvido. El Terrorismo de Estado dos Décadas Después, in Represión y Olvido, Efectos Psicológicos y Sociales de la Violencia Politica dos Décadas Después. Montevideo: Roca Viva, 1995.

21 Dossier internet sobre a tortura, site Web Le Monde.fr, de 27.12.00.

22 Dossier internet sobre a tortura, idem.

23 Dr. Leo Eitinger, Prisión en Campo de Concentración $y$ Traum a tización Psíquica, in Represión y Olvido, op.cit. 
normais, comparáveis, na maior parte das variáveis, num período de observação de 20 anos após a guerra (para a morbidade) e de 30 anos após (para a mortalidade).

Entre os resultados obtidos, aparece claramente que os ex-detidos sofriam mais períodos de doença: enquanto 95\% das testemunhas tinham passado 10 ou menos períodos, isso acontecia só com 18\% dos exdetidos, sendo que $8 \%$ das pessoas torturadas superava os 16 períodos, contra só 1\% nas testemunhas. As internações foram também mais prolongadas: mais de 90 dias para $20 \%$ dos sobreviventes contra 3\% do grupo controle para o mesmo período.

Eitinger assinala que o panorama da morbidade era muito mais amplo do que o esperado, e que, pelo menos em 10\% dos casos, todos os órgãos tinham sido afetados, com um significativo agravamento da situação laboral das pessoas. É de assinalar o fato que as doenças encontradas eram completamente independentes dos fatores prévios à situação de detenção e tortura; pelo contrário, existiu uma clara correlação entre a tortura, os danos cefálicos, o emagrecimento e as condições de detenção.

Uma outra dificuldade para a estimativa da morbidade é a resistência dos afetados em acorrer aos profissionais para serem curados das seqüelas; o Dr. Jean-Louis Guéguen, médico clínico geral dos antigos combatentes franceses na Argélia, estima que, entre dez que precisam de atenção psicoterapéutica, só dois fazem a demanda. No mesmo sentido, o Dr. Bernard Sigg, célebre psiquiatra contrário a essa guerra, observa que os antigos combatentes preferem calar suas angústias e seus medos, afogá-los no álcool, mais do que falar deles ${ }^{24}$.
Se isso acontece com os militares que têm torturado, violado, assassinado, o que dizer das próprias vítimas, das mulheres violadas, dos camponeses, operários e estudantes torturados? Ainda mais se muitos deles têm sido torturados não pelos soldados de uma nação inimiga numa guerra declarada, mas pelos militares e policiais do seu próprio país numa guerra suja? Como avaliar a quantidade de vítimas silenciadas pelo terror e pela impunidade? Como reparar e indenizar essas pessoas?

\section{Mortalidade}

Sendo muito difícil avaliar as taxas de mortalidade por não dispor de dados concretos pelos mesmos motivos expostos acima, tentaremos, porém, fazer uma aproximação a partir dos dados existentes em outros países latino-americanos que têm sofrido a tortura na mesma época que o Brasil, por idênticas razões e realizada pelos mesmos agentes do Estado.

Segundo as estatísticas relativas no Uruguai ${ }^{25}$, a taxa de mortalidade devido aos suicídios nos sobreviventes da tortura é 23 vezes superior à normal do país. Isso também foi comprovado no estudo norueguês antes citado, com uma mortalidade efetiva mais alta diagnosticada nos ex-prisioneiros, que se manteve durante todo o período do estudo (30 anos), sendo que a hipermortalidade foi maior ainda para os jovens do que para as pessoas mais idosas.

Assim, as taxas de mortalidade encontradas por Eitinger nas vítimas de torturas foram superiores à normal (116 contra 100) e também à taxa dos suicídios (91 contra 67). Não devemos esquecer que houve muitos casos de suicídios no exterior, também como seqüela das torturas; basta lembrar o trágico fim de Frei Tito de Alencar Lima, que suicidou no seu exílio, na França, em $1974^{26}$. 


\section{Diagnóstico}

Não tendo uma "síndrome típica" da tortura, com sintomas standard, e sem esquecer que a patologia não está no sujeito, mas na própria situação traumatizante da tortura instituída pelo Estado, só poderemos avançar no tratamento das seqüelas fazendo um diagnóstico apurado o mais cedo possível, com os instrumentos existentes e/ou adaptados, visando, antes de tudo, ao estabelecimento de uma boa relação profissional baseada numa profunda confiança, na solidariedade e na ética, o contrário da cumplicidade. Não devemos esquecer que muitas pessoas foram torturadas com a assistência de médicos e psicólogos (lembremos o tristemente célebre caso do psicanalista e colaborador dos torturadores Amílcar Lobo, no Rio de Janeiro), o que acrescenta a desconfiança dos possíveis consultantes.

Um outro ponto delicado diz respeito à nomenclatura e à nosografia. Na literatura científica, as seqüelas da tortura só têm sido estudadas nos últimos 20 anos, graças aos psicólogos e psiquiatras solidários com as vítimas, como Frantz Fanon ${ }^{27}$, muitos deles também ex-detidos e exilados, como eu mesmo. Na literatura psiquiátrica clássica, só tínhamos alguns capítulos sobre neuroses traumáticas de guerra, escritos depois da Primeira Guerra Mundial, alguns trabalhos de Freud, de Bion e os já citados por Bettelheim. Na concepção freudiana clássica, o trauma é considerado como "aquele que causa, à vida psíquica, num curto lapso de tempo, um incremento de estímulo tal que a solução ou elaboração do mesmo fracassa com os recursos habituais, com o qual surgem permanentes alterações na economia psíquica". Assinalemos, de passagem, o qualificativo freudiano de "permanentes"...
Mais recentemente, os americanos do norte desenvolveram, com a orientação neopositivista do DSM IV, o conceito de PTSD (Post Traumatic Syndrome Disease), que também aparece no IC-10 da OMS (Organização Mundial da Saúde) como TEPT (Transtornos de Estresse Pós-traumático). Em geral, essas classificações têm sido muito criticadas, tanto pelo seu reducionismo quanto pela inversão etiológica subjacente. Com efeito, nessa ótica, o estresse é causado pelo trauma, conseqüência dele, tornando-se, assim, um agente patogênico e deixando na sombra a causa de ambos, a tortura, muitas vezes "naturalizando-a", igualando-a a outras causas (como catástrofes naturais, acidentes do tráfego, etc.).

Ao contrário, pensamos que não pode e não deve ser assim, que as seqüelas vão muito mais longe e são muito mais graves que o simples estresse, que este não é causado pelo trauma, senão pela tortura mesma, e que esta tem uma clara dimensão sociopolítica que não podemos deixar de lado, sem cair na cumplicidade com o terrorismo de Estado que provocou tanto a situação traumática como as suas seqüelas.

Assim, os nossos colegas do Chile ${ }^{28}$ afirmam que o TEPT não parece ser capaz de dar conta de toda a complexidade e magnitude dos processos, tanto individuais como sociais, envolvidos nas seqüelas humanas da tortura; o manual não estabelece indicações específicas a respeito da história prévia do sujeito, a sua estrutura de personalidade, a sua situação de classe, o seu projeto de vida, etc., aparecendo como um sujeito a-histórico, sem biografia, sem nenhuma relação com as redes sociais das quais ele forma parte nem com a sua práxis quotidiana, seja de militância política ou não. Fica claro e comprovado na clínica que as reações e as seqüelas pós-traumáticas serão
Ao contrário, pensamos que não pode e não deve ser assim, que as seqüelas vão muito mais longe e são muito mais graves que o simples estresse, que este não é causado pelo trauma, senão pela tortura mesma, e que esta tem uma clara dimensão sociopolítica que não podemos deixar de lado sem cair na cumplicidade com o terrorismo de Estado que provocou tanto a situação traumática como as suas seqüelas

27 Frantz Fanon, Les Damnés de la Terre Paris:Maspèro, 1961.

28 Dr.Carlos Madariaga Araya, equipe do CINTRAS (Centro de Salud Mentaly Derechos Humanos), Trauma Psico-social, Trastorno de Estrés Post traumático y Tortura, in La Tortura y otras Violaciones de Derechos Humanos op.cit. pp. 33/57. 
muito diferentes em função desses fatores prémórbidos assim como das reações do sujeito aos próprios traumatismos (possibilidade ou não de resistência física e psicológica, de compreensão política da situação - fator chave, segundo Primo Levi e Bettelheim).

O TEPT tampouco dá conta, de maneira satisfatória, da situação social e do contexto político da tortura, privilegiando a quantificação das descargas energéticas num acontecimento inespecífico e abstrato, não incluindo as reações do sujeito social, alvo final da tortura como ferramenta de dominação política. A psicopatologia que deriva desse instrumento e da concepção "científica" e "neutralista" que a sustenta reforça a lógica do poder e a "racionalidade" das estruturas do Estado que instituíram a tortura, fechando, assim, o círculo da cumplicidade.

Essa separação mecânica entre um antes e um depois, com uma situação traumática única que produziria sintomas-padrão num contexto a-histórico, nega, também, os graves problemas das seqüelas devido às seqüências traumáticas, ou re-traumatização ou traumas acumulativos ou recorrentes, segundo as várias denominações científicas.

Assim, não só a realidade clínica dos sintomas excede em muito a "síndrome" PTSD mas também são negados os efeitos retraumatizantes da impunidade dos torturadores (que podem ser dissimulados com monumentos ou com a nomeação de ruas, inclusive com as indenizações às vítimas, como fora e é denunciado pelas Madres de Plaza de Mayo, da Argentina) e as reativações Aires, 01/07/2001.

30 Nas suas peças de teatro "El Sr. Galíndez", e sobretudo, em "Paso de Dos". desaparecimentos, execuções falsas ou verdadeiras, chantagem, etc.; entre os efeitos perversos e re-traumatizantes da impunidade, podemos acrescentar os encontros aleatórios das vítimas com os seus torturadores na rua, no supermercado, etc., várias vezes denunciados, assim como as descobertas tardias de cemitérios clandestinos, tudo isso reabrindo as velhas feridas.

Um outro fator de complexidade sintomatológica do diagnóstico e do tratamento que o diferencia de outros traumatismos é o fenômeno conhecido como "síndrome de Estocolmo"; com efeito, nas relações torturador-vítima, também se estabelecem vínculos identificatórios, transferenciais, de grande intensidade, potencializados pela situação limite mesma e aproveitados, muitas vezes, pelos próprios torturadores para "seduzir" as vítimas. Além da experiência originária, que deu seu nome à síndrome, assim como outras semelhantes mais recentes (p.ex., em julho de 2001, em Buenos Aires, por ocasião de uma tomada de reféns com motivo de roubo num banco Itaú $^{29}$ ), lembremos alguns trabalhos de Eduardo Pavlovsky, psicanalista, institucionalista e dramaturgo argentino, que tem mergulhado nas profundezas desses vínculos inconscientes onde a vítima pode identificar-se com o seu torturador até o ponto de sentir "amor" por ele $^{30}$. Os sentimentos de culpabilidade podem ser intensos, tanto nesse caso como naqueles em que a vítima foi "quebrada", ou simplesmente pelo fato de ter sobrevivido, enquanto os outros morreram.

Por tudo isso, as entrevistas clínicas devem ser feitas com um delicado manejo da transferência e da contratransferência, assim como a análise das implicações do/da psicólogo/a que faz as entrevistas e elabora o relatório final a respeito da tortura como instituição. 


\section{Algumas propostas para um protocolo de trabalho - Entrevistas, instrumentos diagnósticos e prognósticos.}

Dando como certos a experiência profissional prévia do(a) entrevistador(a), um lugar adequado para a realização das entrevistas, uma boa planificação e uma clara explicitação dos motivos das mesmas assim como a devolução dos resultados às vítimas, apresentamos algumas ferramentas e critérios clínicos que estimamos possam ajudar nessa difícil tarefa. Torna-se indispensável analisar com clareza a disposição interna do profissional atuante para esse tipo de entrevistas assim como a sua formação e experiências prévias em situações clínicas limite. Também é muito importante analisar as implicações institucionais do profissional, o estudo da bibliografia sobre esses temas e uma preparação minuciosa do dispositivo das entrevistas, os contatos com as pessoas da população-alvo, assim como prever as conseqüências pessoais e sociais dos relatórios que deverá redigir. No presente trabalho, temos tentado apresentar um amplo panorama da questão (ainda que não exaustivo) para facilitar as tarefas dos colegas e a restituição do direito às vítimas.

Além das considerações já apresentadas, gostaríamos de acrescentar mais algumas sugestões clínicas. É evidente, na experiência internacional, que uma das linhas de trabalho diagnóstico e terapêutico consiste em ajudar a pessoa a recuperar e reparar sua identidade, sendo, para isso, necessário poder ser aceito por ela dentro do seu "enquistamento" (onde, muitas vezes, encontramos aspectos identificatórios com o torturador) assim como ajudar a pessoa a deixar progressivamente o seu papel de vítima e reconquistar ou inventar uma nova identidade, baseada na sua criatividade e nas suas capacidades de afirmação da vida.
As abordagens podem ser diferentes, com orientações técnico-teóricas variadas. Assim, desde a psicanálise freudiana (a do SERSOC, no Uruguai, por exemplo), a terapia de grupos e a técnica da testemunha (como a de Lira e Weinstein, no Chile), desde o psicodrama individual (ver a experiência pioneira de Naffah Netto, no Brasil, op.cit.), a terapia não diretiva (como a do Coletivo COLAT, da Bélgica), a fenomenologia, as terapias existenciais (Frankl), os grupos de apoio, comunitários, associativos, etc., que são freqüentemente utilizados, todos eles necessitam sempre de reformulações dos seus enquadramentos tradicionais.

Uma interessante proposta é a do Projeto Clínico Grupal, elaborado pelo Grupo Tortura Nunca Mais, do Rio de Janeiro ${ }^{31}$, que desenvolve dois eixos de trabalho (atenção e formação), numa prática em que se instala uma relação com a pessoa e não sobre ela. Sem utilizar técnicas especiais, o GTNMRJ propõe tornar visíveis os efeitos transgeneracionais do silêncio que a tortura tem provocado na subjetividade contemporânea a partir da desnaturalização do traumatismo, da reconstrução da história pela táctica da produção da diferença (Deleuze).

Uma modalidade que tem ajudado muito em nossa prática e que se desenvolve progressivamente é a do trabalho em redes, seguindo os aportes fundamentais e as

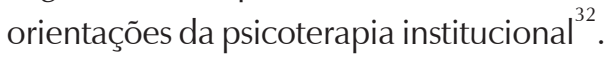

Isso supõe um trabalho em equipe transdisciplinar, apoiado em vários pontos (psicoterapéutico, médico, social, jurídico, fisioterapêutico), orientado para e pelo consultante e seu entorno numa ótica de reparação e prevenção. Clubes terapêuticos e diversas oficinas (artísticas, teatrais, poéticas, etc.) podem ser instrumentos valiosos assim como a formação contínua e a supervisão do trabalho.
31 Vera Vital Brasil, Herramientas para una Práctica Clínica de los Derechos Humanos: la Operación Histórica, in La Tortura y otras Violaciones..., op.cit.

32 François Tosquelles, Horacio Torrubia, Jean Ayme, et. Al, sous la direction de Pierre Delion. Actualitéde la Psychothérapie Institutionnelle, Vigneux :Matrice, 1994. 
Nessa perspectiva, torna-se importante compreender que o que pode curar não é uma interpretação psicanalítica (por mais justa que ela poda ser), nem um medicamento qualquer (mesmo sendo eficaz e indicado), nem um acompanhamento social ou uma orientação jurídica (sempre necessárias). Seguindo Tosquelles, o fundador da psicoterapia institucional, a partir da sua experiência clínica e militante na guerra civil espanhola e nos campos de concentração na França, o que pode curar é o funcionamento o mais autogestivo possível do dispositivo no seu conjunto, é a instituição terapêutica, que precisa, ela mesma, ser "curada" periodicamente para tentar evitar processos contratransferenciais negativos, iatrogenias perigosas que reproduzem e amplificam a patologia que se pretende curar. Essa rede precisa, ainda, desenvolver uma prática social desalienante como coletivo compromissado claramente com a defesa dos direitos humanos.

Nesse sentido, são bem-vindas, entre outras, as iniciativas tais como o projeto "Sementes de Vida", experiência paulista organizada pelo Grupo Tortura Nunca Mais ${ }^{33}$, com atividades de resgate da memória das lutas de resistência, realização de vídeos, campanhas de denúncias, palestras em escolas, formação de monitores, assistência em saúde física e mental, proteção jurídica, parcerias hospitalares, comunitárias, associativas, etc.

Frente à complexidade da problemática clínica exposta, as ferramentas diagnósticas existentes são, lamentavelmente, poucas. Fazendo um esforço de síntese entre diversas abordagens, orientações teóricas, e baseando-nos na experiência própria, podemos sugerir o seguinte protocolo.
Para a avaliação global da pessoa e da sua situação pós-traumática, pode-se utilizar o questionário de Crocq (modificado por nós).

A respeito da avaliação das possíveis seqüelas sensório-motoras, sugerimos o teste de Bender, tanto pela facilidade de aplicação e rapidez de avaliação quanto pela sensibilidade diagnóstica desse teste, sobretudo nos traumatismos cefálicos e na coordenação visomotora; uma outra razão para sua utilização, de muita importância, é que esse teste serve, também (desde a sua criação, há mais de 50 anos), para ajudar na determinação da possível simulação de doenças mentais a partir da análise das estruturas gestálticas subjacentes nas formas desenhadas. É muito importante poder determinar que uma pessoa sofrendo de seqüelas pós-traumáticas não está simulando nada e a sua palavra, o seu testemunho, é psicológica e juridicamente válida.

Para nos aproximarmos da problemática do suicídio e da sua prevenção, podemos utilizar o teste Miokinético de Mira y López, que, sendo também de administração relativamente simples, pode ajudar-nos na determinação precoce das tendências coativo-suicidas que possam, eventualmente, levar a pessoa a provocar situações de risco grave.

A respeito dos problemas de esquema corporal, pode-se utilizar o teste da figura humana, de Machover, completado eventualmente com um "boneco" de madeira, tecido, etc., que é apresentado à pessoa quando está muito inibida para se referir ao seu próprio corpo e pode servir para que ela assinale os lugares corporais mais comprometidos e sensíveis. 
Um exame médico completo (raios X, eletroencefalograma, análise de sangue, fundo de olho, eletrocardiograma, escaneado, etc.), podem ser complementos indispensáveis, assim como um eventual apoio psicotrópico. Os testes habituais de inteligência (Weschler) e de personalidade (projetivos, etc.) podem servir como apoio para certas situações muito particulares, mas não como ferramentas "standard", tanto pelo tempo que eles levam para serem usados como pelo seu possível efeito inibidor.

Não deve se temer um excesso de simulações por parte das vítimas de tortura; com efeito, em toda experiência clínica, tanto pessoal como na dos colegas, o mais freqüente é o comportamento contrário: declarações sóbrias, reservadas, sem nenhum exagero nem dramatizações. No estudo mais completo, o do Dr. Eitinger, na Noruega ${ }^{34}$, ele mesmo exdetido, evidenciou-se que a maioria tinha reprimido as manifestações da sua patologia, a ponto de os profissionais terem que perguntar insistentemente para que eles relatassem os seus padecimentos, que consideravam como parte "natural" das suas vidas, 30 anos depois...

\section{Conclusões a questão da indenização das vítimas}

O estudo do Dr. Eitinger assinala que as doenças encontradas nas vítimas eram independentes dos fatores prévios à situação traumática, mas tinham muita correlação com a tortura sofrida. Devemos sublinhar que esse estudo foi encomendado pelo governo norueguês precisamente pela questão das indenizações às vítimas.

No princípio, os profissionais da saúde estavam surpreendidos e não podiam acreditar que tantas pessoas que sofreram severas cargas psíquicas e que pareciam sadias e aparentemente aptas para trabalhar pudessem adoecer (muitas vezes bruscamente) pelos fatos ocorridos três décadas atrás. Durante os primeiros anos após a guerra, o critério de não causalidade foi mantido, não se podendo estabelecer nenhum vínculo entre as torturas e as doenças 20 anos após; em conseqüência, as indenizações foram sistematicamente negadas.

Num segundo momento, graças aos esforços dos grupos de solidariedade de ex-prisioneiros, organizou-se a pesquisa científica de maneira independente, orientada por profissionais universitários e financiada pelo ministério de saúde. Com efeito, considerando o grande número de pessoas atingidas (mais de 4.500 vítimas), as dificuldades diagnósticas, semiológicas e epidemiológicas apontadas, somadas às reivindicações dos sobreviventes, fizeram com que uma comissão de profissionais tomasse a seu cargo a pesquisa mais completa realizada até agora, com estudos em profundidade com todos os pacientes. Estes não só foram examinados do ponto de vista clínico, médico e psicológico mas também do ponto de vista laboral e social, fazendo tanto estudos transversais (comparativos com a população normal atual) como estudos longitudinais (comparações ao longo dos anos da população-alvo) para detectar eventuais abusos. Tendo já falado dos resultados clínicos, mencionaremos agora aqueles que têm relação com o aspecto da indenização.

Os resultados dessa pesquisa indicam, em primeiro lugar, que o conceito de causalidade linear clássico não pode ser aplicado, levando em consideração que a maior morbidade e mortalidade observadas não se devem a doenças particulares, mas a um conjunto de diagnósticos sem maiores particularidades. Isso confirma o dito anteriormente a respeito da
34 Prisión en Campo de concentración $y$ Traumatización Psíquica, op.cit. 
É importante ter em conta, com Stoffels ${ }^{35}$, que essa é uma outra situação totalmente diferente das "neuroses de guerra" ou "neuroses dos veteranos" ou "neuroses de renda", nas quais a psiquiatria clássica, supondo erroneamente que o trauma pode ser superado por si só depois de um certo tempo, acreditava numa fixação produzida por uma predisposição psicopática e considerava que os sintomas eram "simulações para ter ganhos secundários" (por exemplo, fugir da frente de batalha). não especificidade de uma "síndrome da tortura". A interrogação crítica sobre essa relação causal foi de muita importância para os profissionais da saúde, pois é sobre ela que estava baseada anteriormente a lógica da demonstração do dano e a conseqüente indenização.

Em segundo lugar, depois dessa pesquisa, o critério é o contrário: agora não é a vítima nem o perito que devem demonstrar que a seqüela é um dano duradouro produzido automaticamente pela vivência traumática; é o governo (através das instâncias correspondentes) que deve provar que não existe relação causal entre a tortura sofrida e as seqüelas (por exemplo, nos casos de acidentes de trabalho ou de tráfego, ocorridos depois da situação traumática da tortura). Toda doença de um exprisioneiro torturado é de indenização obrigatória até que possa ser demonstrado que ela não está condicionada a situação traumática.

Em terceiro lugar, o Parlamento norueguês aprovou uma lei complementar para as indenizações que contemplam a situação das pessoas que têm sofrido condições de dureza extrema, torturas, etc., sendo que a decisão final dos juizados responsáveis em outorgar a indenização estava baseada, além das diminuições laborais ou nos estados de inação completa, na existência de estados de angústia crônica ou aguda traumaticamente desencadeada nas vítimas.

Num estudo posterior à aplicação da lei, onde se estudaram os seus efeitos em 1000 pessoas (metade indenizada e metade não), observouse que aqueles que tinham recebido as suas pensões haviam melhorado as suas condições de vida , não só no aspecto material, senão, o que é mais importante, do ponto de vista do reconhecimento social, das relações de casal, dos vínculos sociais e da auto-estima.
Os resultados confirmavam que a lei atuava no sentido esperado, não havendo praticamente fraudes (a relação causal entre os traumatismos da tortura e as doenças invalidantes posteriores não foi encontrada em apenas 7,8 \% dos casos).

É importante ter em conta, com Stoffels ${ }^{35}$, que essa é uma outra situação totalmente diferente das "neuroses de guerra" ou "neuroses dos veteranos" ou "neuroses de renda", nas quais a psiquiatria clássica, supondo erroneamente que o trauma pode ser superado por si só depois de um certo tempo, acreditava numa fixação produzida por uma predisposição psicopática e considerava que os sintomas eram "simulações para ter ganhos secundários" (por exemplo, fugir da frente de batalha).

Tampouco se pode admitir uma aproximação psicanalítica superficial, considerando que são os "traumas da infância" os causadores das seqüelas ou que a situação traumática foi "provocada pelo complexo de castração"... De modo nenhum pode ser assimilada aos traumatismos causados por "acidentes de trabalho" nem aos das catástrofes naturais; com efeito, os critérios habituais para as indenizações por essas situações não correspondem aos traumatismos da tortura. Em primeiro lugar, a tortura não foi "acidental" nem "natural" e, sim, propositada e humana, o que, já na sua origem, produz uma diferença fundamental na caracterização da situação traumatógena. Em segundo lugar, a percepção social do fato é diametralmente oposta: aceitação e solidariedade no primeiro, silenciamento cúmplice e rejeição no segundo. Para terminar, as seqüelas só atingem as próprias vítimas no caso dos acidentes, mas elas são transgeneracionais no caso das torturas.

Um outro fator a levar em conta nas indenizações pode ser o envelhecimento, que torna muito mais frágil o difícil equilíbrio logrado 
pelos perseguidos e torturados, segundo os estudos de Dasberg (1991, citado por Stoffels, op.cit), que também menciona o lugar central do "enquistamento" e da "culpa do sobrevivente" já citados.

Ainda numa outra pesquisa feita por Von Baeyer (1964)citada por Stoffels, em 500 casos de perícia, 38\% das vítimas tinha danos permanentes e 65\% apresentava síndromes reativas tardias. Isso significa que, com o passar dos anos, as vítimas de tortura podem apresentar novos sintomas ou um agravamento dos anteriores, sobretudo nos casos em que não houve nenhum tratamento psicoterapêutico.

De acordo com Viñar (op.cit.), para compreender as relações entre as diversas seqüelas e sintomas, o mais importante não é debruçar-se sobre os detalhes do quadro clínico, e, sim, articulá-los com a história anterior para pesquisar e encontrar os pontos nos quais a constelação identificatória tenha sido estilhaçada; é aí que o trabalho de reparação pode começar, é também aí que a tortura mostra a sua diferença de fundo com os outros traumatismos.

Assim, dizemos com Viñar: "a tortura moderna está programada de maneira inteligente para destruir e desapossar a pessoa da constelação que constitui o seu núcleo de identidade. Em conseqüência, a experiência da tortura não é uma doença curável em tempos que possamos definir; ela constitui uma ruptura da identidade, em parte definitiva (...) quer seja o seu silêncio sintomático ou suas manifestações patológicas... (...) É por isso que nós não identificamos a tortura como um agente produtor de efeitos mórbidos, mas qualificamo-la de experiência que atua reformulando o destino da pessoa e quebrando para sempre um ser humano na sua subjetividade" ${ }^{36}$ (grifos nossos).
Em síntese, podemos dizer, a respeito dos danos e seqüelas psicológicas sofridos pelas vítimas da tortura, baseando-nos na experiência e bibliografia internacionais, que:

- Mesmo não tendo um quadro sintomatológico único nem uma síndrome unívoca, as seqüelas psicológicas são graves e permanentes, com tendência ao agravamento na velhice.

- A matriz da constelação identificatória, base do sentimento de pertença humana e da própria identidade, tem sido atingida no mais profundo do psiquismo.

- A experiência traumática produz seqüelas transgeneracionais.

O índice de psicoses é 5 vezes mais elevado que na população normal.

- A taxa de suicídios é de 16 a 23\% mais elevado.

- A inserção social é muito difícil; as rupturas familiares são freqüentes.

- A capacidade laboral fica muito diminuída, às vezes, até impossibilitada.

Além do traumatismo inicial, devem ser levados em conta os efeitos agravantes produzidos pela retraumatização posterior.

- Alguns sintomas de seqüelas aparecem logo depois de longos períodos aparentemente assintomáticos (20, 30 anos após...).

- As doenças físicas, as hospitalizações, as intervenções cirúrgicas, etc., são mais graves e freqüentes.

- As pessoas vítimas de tortura não consultam facilmente (só o fazem $20 \%$, em média), as 
porcentagens de "fraude" e "simulação de doença" são baixíssimas, e as entrevistas administrativas podem reativar sintomas e sofrimentos.

Além da indenização de acordo com os danos sofridos, é indispensável oferecer às vítimas uma atenção psicoterapêutica, médica, social e jurídica especializada em relação com a gravidade da experiência traumática vivida. Tendo finalizado esta breve análise da problemática clínica nos seus diferentes aspectos, tentaremos expor alguns instrumentos que, utilizados com prudência, podem ser complementares às entrevistas diagnósticas e ajudar na determinação dos danos sofridos, dos possíveis danos no futuro e das orientações terapêuticas recomendáveis.

Alfredo Guillermo Martín

Psicólogo, analista institucional, Doutor em Ciências da Educação (Universidade Paris VIII). Professor de Psicologia da Universidade Federal de Rio Grande. Rua Arroio Grande 374 - Cassino 96206-050 Rio Grande/RS E-mail:martingen@ibest.com.br 
ANTELME R. L’Espèce Humaine. París: Gallimard, 1957.

AMNESTY INTERNATIONAL. Rapport sur la Torture. Paris: Gallimard 1973.

. Les Assassinats Politiques. Rapport sur la Responsabilité des États. Paris: du Seuil, 1983

. La Torture, Instrument de Pouvoir, Fléau à Combattre. Paris: du Seuil, 1984.

ALLEG, H. A Tortura, incluindo "Uma Vitória", de Jean Paul Sartre, São Paulo: Zumbi, 1959

ARQUIDIOCESE DE SÃO PAULO, prefácio de Dom Paulo Evaristo Arns. Brasil: Nunca Mais. Petrópolis: Vozes, 1986.

Autores vários. Daño Psicológico y Crisis Política. Simpósio em Santiago do Chile (mimeografado), abril, 1980.

BAREMBLITT, G. Compêndio de Análise Institucional e outras Correntes - Teoria e Prática. Belo Horizonte: Instituto Félix Guattari, 2002.

1984.

O Inconsciente Institucional. Petrópolis: Vozes,

Barudy, J., Paez D., e outros (Grupo COLAT). Psicopatologia de la Tortura y del Exilio. Madrid: Fundamentos: Sudamericana-Planeta, 1982 (possui edição em inglês).

BERMANN, S., EDELMAN, L., KORDON, D., MULLER-HOAGEN, J., PAVLOVSKY, E., STOFFELS, H., VIÑAR, M. Efectos Psicosociales de la Represión Política, sus Secuelas en Alemania, Argentina y Uruguay. Córdoba, Argentina: Goethe Institut, 1994.

BETTELHEIM, B. O Coração Consciente, Paris: Robert Laffont, 1987.

Survivre, Paris: 10/18, 1996

COIMBRA, C. Guardiães da Ordem: uma Viagem pelas Práticas Psi no Brasil do "Milagre". Rio de Janeiro: Oficina do Autor, 1995. Comitê Médico-Social pour la Santé des Migrants, Consultation Psychologique des Réfugiés, Migrants et Démandeurs d'Asile. Bilan Annuel des Consultations et des Réseaux Ethnopsychologiques. Toulouse: CMSSM, 1994/2000.

EATIP (Equipo Argentino de Trabajo e Investigación Psicosocial), CINTRAS (Centro de Salud Mental y Derechos Humanos de Chile), GTNM/RJ (Grupo Tortura Nunca Mais, do Rio de Janeiro), SERSOC (Servicio de Rehabilitación Psicosocial de Uruguay). Paisajes del Dolor, Senderos de Esperanza. Salud Mental y Derechos Humanos en el Cono Sur. Buenos Aires: Polemos, 2002

Equipo de Estudios Comunitarios y Acción Psicosocial (ECAPGuatemala), Oficina de Derechos Humanos del Arzobispado de Guatemala y Consejo Internacional para la Rehabilitación de Víctimas de la Tortura (IRCT-Dinamarca) (org.). Primer Seminario Latinoamericano y del Caribe: Modelos de Abordaje para Personas Afectadas por la Tortura y otras Violaciones de los Derechos Humanos. Guatemala, abril de 2000.

Equipe Clínico-Grupal Tortura Nunca Mais. Intervenção Clínica quanto à Violação dos Direitos Humanos: por uma Prática Desnaturalizadora na Teoria, na Ética e na Política. In Anuário do Laboratório de Subjetividade e Política, ano II, vol. II. Rio de Janeiro: UFF, 1993. EYMERICH, N. (1376) Revisto e ampliado por Francisco de La Peña (1578), prefácio de Leonardo Boff. Directorium Inquisitorum. Manual dos Inquisidores. Rio de Janeiro: Rosa dos Tempos. Brasília, DF: Fundação Universidade de Brasília, 1993.
FANON F. Les Damnés de la Terre. Paris:Maspèro, 1961. Edição espanhola: Los Condenados de la Tierra. México:Fondo de Cultura Económica, 1963.

FASIC (Fundación de Ayuda Social de las Iglesias Cristianas). Trauma Duelo y Reparación, una Experiencia de Trabajo Psicosocial en Chile. Chile: Interamericana, 1987

FRANKL, V. Um Psicólogo no Campo de Concentração. Lisboa: Áster, s/d. Trad. espanhola: El Hombre a la Búsqueda de si Mismo. Barcelona:Herder, 1994

GIORGI V. (compilador) y equipo de salud mental del SERSOC (Servicio de Rehabilitación Social). Represión y Olvido. Efectos Psicológicos y Sociales de la Violencia Política dos Décadas Después. Montevideo: Roca Viva, 1995.

JERVIS, G. La Tecnologia de la Tortura. In La Ideologia de la Droga y la Cuestión de las Drogas Ligeras. Barcelona: Anagrama, 1977. KEIL, Y., TIBURI, M. (org). O Corpo Torturado. Porto Alegre: Escritos Editora, 2004

LEVI P. Les Naufragés et les Rescapés. Quarante Ans après Auschwitz. Paris: Gallimard, 1989.

NAFFAH NETO, A. Poder, Vida e Morte na Situação de Tortura São Paulo: Hucitec, 1985.

Núcleo de Profissionais da Saúde do Comitê Brasileiro pela Anistia. Estudo sobre a Tortura no Brasil. São Paulo, (mimeografado), s/d. KORDON, D., EDELMAN, L. y otros (Equipo Psicológico de Madres de Plaza de Mayo). (1986). Efectos Psicológicos de la Represión Política. Buenos Aires: Le Monde (periódico francês). Torture et Tortionnaires, Dossier no 99. Paris:Le Monde, março 1983.

Les Séquelles de la Guerre. 350.000 Anciens d'Algérie Souffriraient de Troubles Psychiques Liés à la Guerre. Dossier WEB 27/12/00. Paris: Le Monde, 2000.

LIRA, E., WEINSTEIN, E. e outros. Psicoterapia y Represión Política. México: Siglo XXI, 1984.

PENNA SATTAMINI, E. Esquecer? Nunca Mais... (A Saga de meu Filho Marcos P.S. de Arruda). Rio de Janeiro: Productor Editoria Independente, 2000.

SASTRE, S. La Psicología, Red Ideológica. Buenos Aires: Tiempo Contemporáneo, 1974

VI Simpósio Internacional. “La Tortura. Un Desafío para los Médicos y otros Profesionales de la Salud". Buenos Aires, Argentina, octubre de 1993.

SIRONI, F. Les Victimes de Torture et de Represión: Nature Singularité et Fonction du Traumatisme. Paris:Psychologie Medicale, vol. 24, no 5, 1992

Une Pratique sous Influence: Psychothérapie avec les Victimes de Torture. Nouvelle Revue de Etnopsychiatrie, no 22/23. Grenoble:La Pensée Sauvage, 1993.

Psychopathologie de la Torture. Paris: Odile Jacob, 1997. TOSQUELLES, F., TORRUBIA, H., AYME, J., et. al, sous la direction de Pierre Delion. Actualité de la Psychothérapie Institutionnelle. Vigneux: Matrice, 1994.

VARGAS, I. Guerra é Guerra, Dizia o Torturador. Rio de Janeiro: Codecri, 1981.

VIÑAR, M. Exil et Torture. Paris: Denöel, 1989.

\section{Referências}

